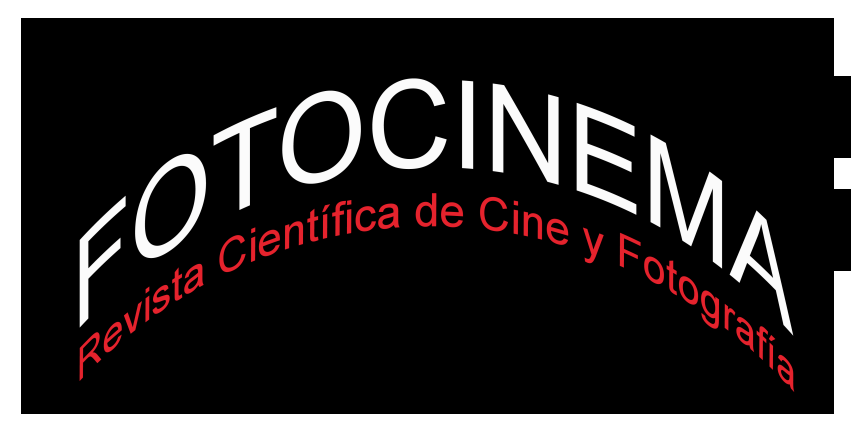

\title{
COMPOSICIÓN Y (DES)COMPOSICIÓN: ESPACIO Y SIGNIFICADO EN IDA
}

\section{FRAMING AND DEFRAMING: SPACE AND SIGNIFICANCE IN IDA}

\author{
Rafael Suárez Gómez \\ Tecnocampus, adscrito a Universitat Pompeu Fabra, Espanya \\ rsuarezg@tecnocampus.cat
}

\section{Resumen:}

La importancia de la composición en el hecho cinematográfico como elemento fundacional y fundamental del mismo puede comprenderse en el momento en que se diferencia entre tipos de composición. Esta herencia del aparato fotográfico muestra que la ruptura de la composición institucional hace emerger diferentes opciones compositivas que rompen con la importancia del centro, mostrando la posibilidad de ampliación que el significado de una imagen puede contener a partir de los elementos que sus creadores escogen en el momento de componerla. Este es el caso de Ida (2013), de Pawel Pawlikowski, cuya fotografía y trabajo compositivo añaden significado a cada una de sus imágenes de forma individual y en el conjunto del film gracias al estilo fotográfico en el que sitúan sus referentes. Con el objetivo de mostrar estos aspectos se realiza un análisis del film a partir de conceptos relacionados con la composición figurativa, reflexiva $\mathrm{y}$ aleatoria. Estos conceptos se reúnen en una definición de lo que se denomina como (des)composición.

\begin{abstract}
:
The importance of composition in the cinematographic fact as a foundational and fundamental element can be better understood knowing the difference between types of composition. This inheritance of the photographic apparatus shows that the rupture of the institutional composition rises to different compositional options that break with the importance of the center, showing the possibility of enlargement of the image's meaning related to the elements that its creators choose when composing it. This is the case of Pawel Pawlikowski's Ida (2013), whose cinematography and composition work adds meaning to each one of the images individually and in the whole of the film thanks to the chosen look marked by his photographic referents.

With the objective of showing these aspects this article analyses the film with concepts related to figurative, reflexive and aleatory composition. These concepts are reunited in a definition of what's been articulated as deframing.
\end{abstract}

Palabras clave: composición; (des)composición; encuadre; cinematografía; Ida.

Keywords: Framing; Deframing; Frame; Cinematography; Ida. 
Cómo citar: Suárez Gómez, R. (2018). Composición y (des)composición: espacio y significado en Ida. Fotocinema. Revista científica de cine y fotografía, no 16 , pp. 197-222.

Disponible: http://www.revistas.uma.es/index.php/fotocinema/

DOI: http://dx.doi.org/10.24310/Fotocinema.2017.voi16

\section{Introducción: la fotografía cinematográfica de Ida}

Quería que el espectador se acostumbrará pronto al hecho de que su vista no va a ser guiada a algo y luego a otra cosa. [...] Hay muchos planos generales, así que el ojo tiene que acostumbrarse. Tienes que mirar realmente la película. [...] Mi espectador ideal comprende que las imágenes son tan emocionales como las actuaciones [...]"1 (Bergery, 2014, p. 57).

Estas declaraciones de Pawel Pawlikowski ponen de manifiesto sus intenciones en Ida (2013), la historia de una joven monja en busca de su verdadera identidad en la Polonia comunista de los años sesenta. La película de Pawlikowski recibió el reconocimiento internacional de crítica y público, resaltando entre otros aspectos su fuerte fotografía -tal y como la adjetiva el propio director- y el uso que hace de la composición. Por este motivo, realizar un análisis de lo que en los estudios anglosajones ha sido denominado como framing - a partir de ahora traducido como componer o encuadrar- y deframing - a partir de ahora traducido como (des)componer o (des)encuadrar ${ }^{2}$ - a partir de sus imágenes permite resaltar aspectos significativos en relación a la composición y el encuadre como elementos esenciales del hecho cinematográfico y su recepción por parte de los espectadores. Al mismo tiempo, la propuesta estética elaborada por los cineastas para Ida implica una relación directa con aspectos propios de la pintura y la fotografía, convirtiendo el espacio fílmico en un punto de conexión entre estas diferentes disciplinas con el ánimo de fusionar algunas de sus características más destacadas. Por este motivo, en adelante se realiza

\footnotetext{
${ }^{1}$ Esta y el resto de traducciones de citas extraídas de textos en otro idioma son del autor.

2 Se prefiere utilizar estas expresiones frente al término utilizado, por ejemplo, en la traducción de La imagen (Aumont, 1992), donde se hace referencia al original décadrage como sobreencuadre (1992, p. 164) o desencuadre (1992, p. 167).
} 
un análisis de los términos que transitan entre estas diferentes artes (componer y (des)componer) poniendo especial énfasis en los aspectos cinematográficos y haciendo referencia a las relaciones que se establecen con los campos de la pintura y de la fotografía en relación al concepto de póster que sus propios creadores utilizan para hacer referencia a las composiciones que integran en el conjunto de la película.

\subsection{Objetivos}

El análisis que se aplica a Ida a modo de estudio de caso tiene como objetivo principal describir los aspectos compositivos que hacen del film un ejemplo de ruptura con lo que se denominará como composición institucional. Este objetivo se relaciona también con la carga psicológica que contiene el uso de una composición que rompe con lo institucional y se centra en comprobar su influencia en la lectura que el espactador hace del arco del personaje principal. A su vez, un tercer objetivo es comprobar si esa supuesta ruptura con la composición institucional genera una interpretación del espacio (en relación con el elemento pictórico y fotográfico de la imagen) y el tiempo (en relación con el elemento fílmico) con significantes relevantes en Ida. En este sentido, se presentan aspectos teóricos relacionados con los conceptos de composición y (des)composición, al mismo tiempo que se utilizan los aspectos más esenciales de la composición como disciplina transversal a las diferentes artes figurativas.

\section{Marco teórico: Componer y/o cortar}

Desde los experimentos llevados a cabo por los cineastas soviéticos de principios del siglo $\mathrm{XX}$, el corte $\mathrm{y}$ sus funciones semántica, sintáctica $\mathrm{y}$ rítmica han sido tomados como primordiales en la generación de significado dentro de un discurso fílmico. Sin negar este factor, el presente artículo se centra en los estudios sobre el concepto de composición o cuadro como acto fundacional y fundamental del hecho cinematográfico, emparentándolo así con otras artes figurativas como la fotografía o la pintura. En esta línea, Gerald Mast (1984) proponía recuperar la preponderancia del cuadro, más 
allá de la unión entre planos, ligando su teoría con las premisas de Bazin acerca de la comprensión del espacio cinematográfico como campo de batalla donde narrar mediante el uso de la profundidad de campo, la duración de los planos o la recomposición cuando es necesaria -entendiendo por recomposición o reencuadre la modificación del encuadre para mostrar la acción-. Por tanto, un estudio centrado en el acto de componer se aproxima a elementos propios del montaje y ritmo interno, que implica que "en el interior del mismo plano coexisten unidades significantes distintas que son, en la práctica discursiva fílmica, tratadas de formas distintas y organizadas entre sí con arreglo a criterios de montaje”, tal como señala Sánchez Biosca (1991, p. 177). Sin embargo, el mero hecho de referirse a estos aspectos bajo la acepción de montaje interno indica la subordinación a la que la composición está sujeta conceptualmente. Por esta razón se reivindica una relectura del acto de componer como expresión distinta a la del montaje en tanto que "el cuadro cinematográfico no es un contenedor vacío; es un significante activo" (Mast, 1984, p. 85), tal y como sucede en la fotografía o la pintura.

Esta reivindicación pretende mostrar la necesidad de concentrarse en la composición como elemento de estudio y discusión con el objetivo de mostrar qué función y qué aspectos es capaz de reforzar en el mensaje cinematográfico y sus significantes. En definitiva, se trata de obtener para la composición un espacio diferenciado del corte en tanto que aspecto ontológico de la imagen cinematográfica que no puede ser medido simplemente en términos de duración. Sin embargo, esto no implica dejar el posterior análisis de Ida supeditado al significado de un plano desconectado del resto de unidades de un sintagma fílmico sino que implica que el análisis debe centrarse en cómo la composición de una imagen puede estar cargada de significado, influyendo en la lectura que el espectador hace no solo de ella sino del conjunto que conforma una secuencia o film completo. Es decir, en la relación que existe entre la cinematografía y otras artes ilustrativas como la pintura y la fotografía, donde a partir del ritmo y emoción internos de la obra aparecen significantes propios. 


\subsection{Componer, (re)componer, (des)componer}

En primer lugar, es necesario destacar que la composición es un concepto complejo que incluye toda una serie de parámetros técnicos y estéticos básicos de la imagen que la relacionan directamente con artes como la pintura o la fotografía, pero que incluye también características propias del medio cinematográfico como su naturaleza temporal y cambiante. En este sentido, una propuesta de definición de los aspectos que incluye se puede encontrar en The Complete Film Dictionary (Konigsberg, 1993, p. 70), donde se indica que los responsables de la composición cinematográfica son los directores, directores de fotografía y operadores de cámara, así como los responsables de la dirección artística, el vestuario o el maquillaje. Asimismo, se señala que el diseño visual de un plano va más allá de la realización de una imagen sin significado, incluyendo aspectos como la organización de las fuerzas que forman parte del cuadro, las reglas propias de la composición como la básica regla de los tercios, el uso del aire, etc.-, la tipología de planos o la iluminación. Todos estos elementos deben ser considerados herramientas para conseguir la empatía, emoción e interés del espectador (Brown, 2012). Por tanto, entran en juego todos los elementos propios de la cinematografía en tanto que escritura de imágenes en movimiento. Por este motivo, se considera importante diferenciar entre componer y encuadrar, en tanto que la composición es fruto del trabajo de todos los responsables de la imagen, mientras que el encuadre se refiere a la decisión final en relación a la posición de cámara, óptica y elementos que conformaran el campo visual.

Esto implica que el trabajo sobre la composición se viene realizando desde los inicios del cine como herencia de la fotografía y la pintura, por lo que esa serie de principios básicos que conforman sus reglas están basados en la necesidad de dirigir la mirada del espectador y su respuesta emocional. Este aspecto de la composición queda confirmado por definiciones como la de Aumont (1992, p. 164), en la que se indica que en el lenguaje cinematográfico centrar y componer son términos intercambiables que se aplican al trabajo realizado para guiar la mirada del espectador. Estos principios serán 
denominados a partir de ahora como composición institucional en referencia al modo en que Burch utiliza el término (1970).

El segundo de los elementos a resaltar, la (re)composición (traducción del término reframing), alude a la necesidad de modificar el ángulo de visión de la cámara para ofrecer la información más relevante para el espectador en cada momento, entendiendo este aspecto como parte del montaje interno movimiento de cámara- o como parte del montaje externo -corte y cambio de ángulo para avanzar emocionalmente en la narración (siguiendo las reglas propuestas por Walter Murch (1992, p. 17-20)-.

El tercer aspecto es el asociado al concepto traducido habitualmente como desencuadre y que se prefiere denominar como (des)composición o (des)encuadre en tanto que conjunto de técnicas propias que rompen la centralidad de la imagen y las reglas institucionales para su construcción. El origen del término es el francés décadrage, posteriormente traducido al inglés como deframing. El crítico Pascal Bonitzer (1978) utilizó el término con el objetivo de describir un modo de componer la imagen donde se rompe con el imperio del centro entendido a partir de las diferentes acepciones a las que se refiere Arnheim (1981). En concreto, Bonitzer define el décadrage como una "composición desviada" (Wilson, 2000, p. 200) que tiene algo de perverso, irónico y sádico en su ruptura de la composición institucional ya que llama la atención sobre si misma. Esta concepción de la (des)composición -décadrage es utilizado también por Deleuze o Derrida para tratar la relación entre el cuadro y sus límites en la pintura- muestra que puede ser aplicada al análisis cinematográfico para evidenciar prácticas compositivas que rompan con el equilibrio del cuadro y el punto de vista aprehendido como parte de una gramática y retórica iniciada especialmente por Griffith. Es necesario, por tanto, diferenciar entre una composición institucional que enfatiza el centro de la imagen y la (des)composición, generando esta segunda una ruptura que obliga al espectador a llenar los vacíos generados o dirigir su atención hacia espacios del cuadro no habituales, realizando una relectura del significado de aquellos espacios que normalmente están adscritos a la composición habitual (Sevin, 2007, p. 16). 
Como conclusión sobre el concepto de (des)composición, hay que destacar la clasificación que presenta O’Rawe (2011) sobre diferentes tipos de composición visual. En primer lugar, la composición indiscernible hace referencia al estilo que encontramos en la mayoría de producciones comúnmente denominadas comerciales. Por este motivo indica que las reglas del realismo marcadas por la continuidad y la narración «sin costuras» demandan que una película nunca tome protagonismo en si misma como película en si, como un artefacto estético" y que "en cierto sentido, el cuadro, como el corte, no existe (2011, p. 2). En este punto, nos encontraríamos en lo que se ha denominado composición institucional.

Las otras categorías que O’Rawe diferencia son la composición figurativa -la de aquellas producciones donde se hace un uso de la composición caracterizado por las distorsiones o desencuadres que buscan generar un efecto figurado- y la composición reflexiva -donde se rompe con las convenciones cinematográficas de una forma consciente y deliberada al modo en que Godard subvierte las reglas establecidas tanto en su uso del montaje como del encuadre-. Finalmente, se contempla una cuarta opción, la composición aleatoria, donde no son decisiones cinematográficas las que llevan a la realización de un cuadro concreto, sino que el resultado del mismo es fruto de accidentes o contingencias.

Dejando de lado la composición indiscernible, las otras tres opciones que señala O’Rawe pueden entenderse como aspectos que complementan la presentación del concepto de (des)composición. A partir del análisis de Ida se podrá llegar a una reflexión final que reúna las implicaciones de estas en tanto que tipos de composición que rompen con el énfasis del equilibrio y centralidad, ya que (des)componer, tal y como indica Aylan, "siempre es una intención estilística o método ideológico para escapar de los regímenes convencionales" (2007, p. 23). 


\section{3. (des)composición en Ida}

Ida presenta unas características técnicas propias de los referentes cinematográficos y fotográficos utilizados para documentar los años sesenta en la Polonia comunista por parte de su director. En este punto se encuentra uno de los aspectos más significativos en relación a la reunión de fotografía y cinematografía en el proceso de creación de esta obra. Esta relación es fundamental, ya que se trata del motivo por el que la película presenta un tratamiento basado en el blanco y negro y una relación de aspecto de 1:1,33, relación de aspecto académica previa a la inclusión de la banda sonora en la película fotoquímica. El blanco y negro y la relación de aspecto son fundamentales en la propuesta estética y compositiva de Pawlikowski y sus directores de fotografía, Ryszard Lenczewski y Lukasz Zal3, dentro de una intención claramente marcada por utilizar “nada más allá de lo esencial”, tal y como declara el propio Pawlikowski. Este motivo lleva a indicar a Lukasz en el mismo artículo que "desde el momento en que decidimos prescindir de elementos fotográficos como el color y el movimiento de cámara, me centré en buscar una identidad apropiada a la historia a través de la composición y el encuadre" (Larumbe, 2014, p. 25).

Ciertamente, los elementos fotográficos que están ausentes de forma generalizada a lo largo de todo el metraje de forma característica son los movimientos de cámara y la utilización de espacios sin presencia de personajes en el tercio superior de la imagen. Este aspecto se encuentra a lo largo del film sea cual sea la tipología de plano utilizado, desde generales donde suele ser más habitual o institucional- hasta primeros planos, contando algunas excepciones. En este sentido, es esencial señalar como punto de partida las declaraciones del director en relación a este aspecto:

[...] cuando analizas intelectualmente la composición, puedes decir que es sobre la ausencia de los millones, o la falta de Dios, o incluso la presencia de Dios... y me complace mirarlo de ese modo, pero no fue el principio que

\footnotetext{
3 Ryszard Lenczewski realizó la fase de preproducción y los primeros días de rodaje, el cual abandonó debido a una enfermedad, dejando a su operador de cámara al mando de la fotografía de la película, Lukasz Zal, del que cabe destacar que fue su primera dirección de fotografía para un largometraje (Larumbe, 2014).
} 
seguimos. La composición no se decidió intelectualmente; simplemente parecía correcta de algún modo. Empezamos preguntándonos ‘Cómo podemos hacer este formato más interesante?'. Entonces, después de hacerlo algunas veces, comprendes que algo está sucediendo que sugiere significado. (Bergery, 2014, p. 57-58).

A esto se debe sumar que Lukasz Zal también indica que "fue una decisión basada más en la intuición que en el razonamiento intelectual" (Larumbe, 2014, p. 22) y que "la tensión en los cuadros habla sobre las almas de nuestros personajes y su mundo" (Bergery, 2014, p. 57).

Estas declaraciones sitúan el modo de encuadrar en Ida en una interacción entre la composición figurativa, reflexiva y aleatoria, ya que se busca tanto generar efectos figurados a través de un trabajo de (des)composición, efecto que se encuentra de forma un tanto aleatoria, como romper con los cánones más tradicionales:

[...] realizamos unas elecciones muy precisas, como el formato 1:1,33. Es un formato muy bueno para los rostros, pero no para los paisajes, y no me terminé de convencer hasta que, de manera intuitiva, decidí inclinar un poco la cámara para dar más aire a los personajes, creando la sensación de que las figuras se pierden en el paisaje de manera vertical, y no horizontal como suele ser habitual. Todas estas elecciones están encaminadas a crear una película meditativa, que genera un espacio para la imaginación que los espectadores deben llenar. (Albero, 2014, p. 45)

Debido a estas características formales, el interés del análisis es dirigirse hacia los aspectos de (des)composición en la relación que se establece entre el espacio de la composición y sus significantes en tanto que evolución de la protagonista. Es decir, se trata de comprobar si el poder psicológico que añade la (des)composición en Ida escapa del concepto de pósters que el propio Lukasz Zal aplica para referirse al modo en que se planteaban las escenas de la película: "amplios, estáticos encuadres que encierran a los personajes y transmiten la historia y el estado de ánimo" (Bergery, 2014, p. 56). Estos pósters sitúan al film en relación con la obra de artistas tanto del campo de la fotografía como de la pintura, siendo Edward Hopper uno de los referentes que se pueden relacionar directamente con las propuestas 
cinematográficas de Zal y Pawlikowski en el tratamiento de la soledad (a pesar de la ausencia de color), así como se ha relacionado con tantos otros cineastas (De Pablos, 2005), debido al elemento de "desasosiego, una cierta sensación de atmósfera enrarecida, provocando un sentimiento de inestabilidad en quienes lo contemplan" (Roda, 2015, p. 88). Al mismo tiempo, relacionado con directores de referencia para Pawlikowski, se puede resaltar también una utilización de la luz y el espacio relacionada con Dreyer y, por consiguiente, con el pintor danés Vilhelm Hammershøi y sus "callados universos visuales" (Fonsmark, 2007, p. 24).

Cabe destacar que la mayoría de secuencias que componen Ida cuentan con una media de uno a tres planos que no siguen de forma rígida las reglas de cobertura fílmica tradicional. Por este motivo la relación entre el arte fotográfico, pictórico y cinematográfico cobra un significado especialmente relevante en tanto que se trata de una propuesta que rompe con la composición institucional y el modo en que se trabajan las escenas a partir de los diferentes planos que las cubren de forma tradicional. De esta relación en la que cada póster -convirtiendo así los encuadres en una especie de fotografía o de pintura- tiene un peso específico y marcado, la película se traslada de lo fotográfico individual a lo diegético cinematográfico sin alejarse de esa conexión establecida y fundacional del film. Por esta razón, el análisis se centra en la protagonista y su arco de transformación a través de aspectos relacionados con el encuadre y (des)encuadre en tanto que parte del acto de componer y/o (des)componer que se convierte en un diálogo entre el arte fotográfico y pictórico -imagen fija- y cinematográfico -imagen tiempo- a lo largo de la película.

Para realizar este estudio se ha utilizado la metodología de análisis de contenido con el objetivo de realizar una interpretación de los contenidos indirectos (Abela, 2003) de las imágenes de Ida, es decir, interpretar los significantes de sus imágenes y no solo sus significados (Igartua y Humanes, 2004). Esta interpretación se ha realizado a partir de un método sistemático basado en la observación directa a partir de las categorías propias de la composición institucional presentadas en el marco teórico con la finalidad de 
observar e indicar si se produce una ruptura de esas mismas reglas. Con este objetivo, se ha dividido la película en un total de nueve capítulos en función de elementos narrativos fundamentales de la trama ${ }^{4}$. Posteriormente se ha realizado una captura de un fotograma identificativo (o dos si era necesario por cambios relevantes en el cuadro) de cada uno de los planos que componen la película (un total de 273) y se han dividido en función de su pertenencia a los capítulos utilizados. A partir de aquí se ha iniciado el análisis visual, escogiendo las imágenes más representativas relacionadas con el objetivo de la investigación, es decir, en función de su composición y su valor dramático en la trama. A continuación se presentan los resultados obtenidos mediante este análisis.

\subsection{Anna}

El primer capítulo es la presentación de la protagonista en el convento en el que vive a la espera de ser ordenada monja. Estos primeros cinco minutos de metraje presentan a Ida en sus labores diarias y el conflicto al que deberá enfrentarse: su nombre no es Anna y para poder conocer su verdadera identidad deberá abandonar el convento para visitar a su tía Wanda en la ciudad.

A nivel de composición, esta primera parte se caracteriza por los elementos descritos anteriormente: no hay movimiento de cámara y todos los planos incluyen el tercio superior de la imagen con un vacío que anuncia la constante presencia que tendrá a lo largo de la película. Cabe destacar, por tanto, en relación a la evolución del film y el personaje, que Ida es presentada a partir de esa tensión en el cuadro que genera un peso psicológico que la sitúa en una situación de aflicción y ruptura de la normalidad. Por tanto, se puede señalar que la descripción del personaje depende también del poder psicológico de la (des)composición, más allá del montaje.

Otro aspecto a señalar como diferencial se encuentra en la conversación con su madre superiora -el personaje que desvela su falsa identidad-, en la que

4 Los capítulos en los que se ha dividido Ida son: 1.Anna; 2.Wanda; 3.Ida y Wanda; 4.Lis, primer encuentro; 5.Final de la búsqueda y segundo encuentro; 6.Vuelta al convento; 7.Suicidio; 8.Sexo; 9.Cierre. El contenido de los mismos se indica en cada punto del análisis que se inicia a continuación. 
los tradicionales plano-contraplano de diálogo se ven modificados: no solo el tercio superior de la imagen queda vaciado, sino que el uso del aire de los personajes es también contrario al habitual, haciendo que sus miradas choquen contra los límites del cuadro, representando de forma figurada la separación que existe entre los personajes, tal y como se puede observar en los fotogramas superiores de la figura 1.

\subsection{Wanda}

La presentación de Wanda es fundamental en el desarrollo de la obra. Supone el inicio de la búsqueda de los cadáveres de sus familiares, aspecto que lanza la trama -como conflicto externo-. Al mismo tiempo supone la presentación de un contrapunto al personaje de Ida que implica subrayar su conflicto interno al situarla ante la posibilidad del mundo real frente a la realidad enclaustrada del convento.

En este capítulo, que va desde el minuto cinco de metraje hasta el doce, se utilizan también elementos compositivos propios del estilo visual del largometraje: aires en la zona superior de la imagen y presencia de elementos en el cuadro en forma de líneas de ruptura de la horizontalidad y la verticalidad para reforzar la intranquilidad de la protagonista. Sin embargo, existen diferencias importantes.

Por ejemplo, al inicio del capítulo, hay uno de los pocos planos en movimiento: una cámara situada en el punto de vista de la protagonista, observando las calles de la ciudad a través del cristal del ferrocarril en el que viaja. Este mismo plano se inicia con una transición a modo de barrido a partir del cruce con otro ferrocarril, lo que unido al movimiento no estabilizado de la cámara permiten reforzar el estado psicológico de Ida en el momento en que se enfrenta a una realidad distinta. Este aspecto se subraya en el siguiente plano, en el que vemos a Ida mirando desde el interior del ferrocarril. En este caso, este primer plano no cuenta con el característico aire en el tercio superior de la imagen. A esto se suma el reflejo de las imágenes que Ida observa, con lo que se genera una sensación muy concreta de atención por parte del espectador en relación a lo que sucede a la 
protagonista y permite, por tanto, jugar un papel psicológico en la acción que sucede (figura 1, inferior izquierda). Por lo tanto, en este caso la composición utilizada, siendo más institucional, tiene la finalidad de producir una lectura básica de la emoción del personaje. Además, el aire vuelve a jugarse en el espacio contrario al institucional, por lo que esa emoción está construida a partir de los elementos compositivos unidos a los propios del mecanismo narratológico de la película.

Este fragmento es uno de los que rompe de forma más clara con los referentes fotográficos en tanto que se utilizan técnicas propias de la cinematografía que implican el movimiento y la cámara en mano.

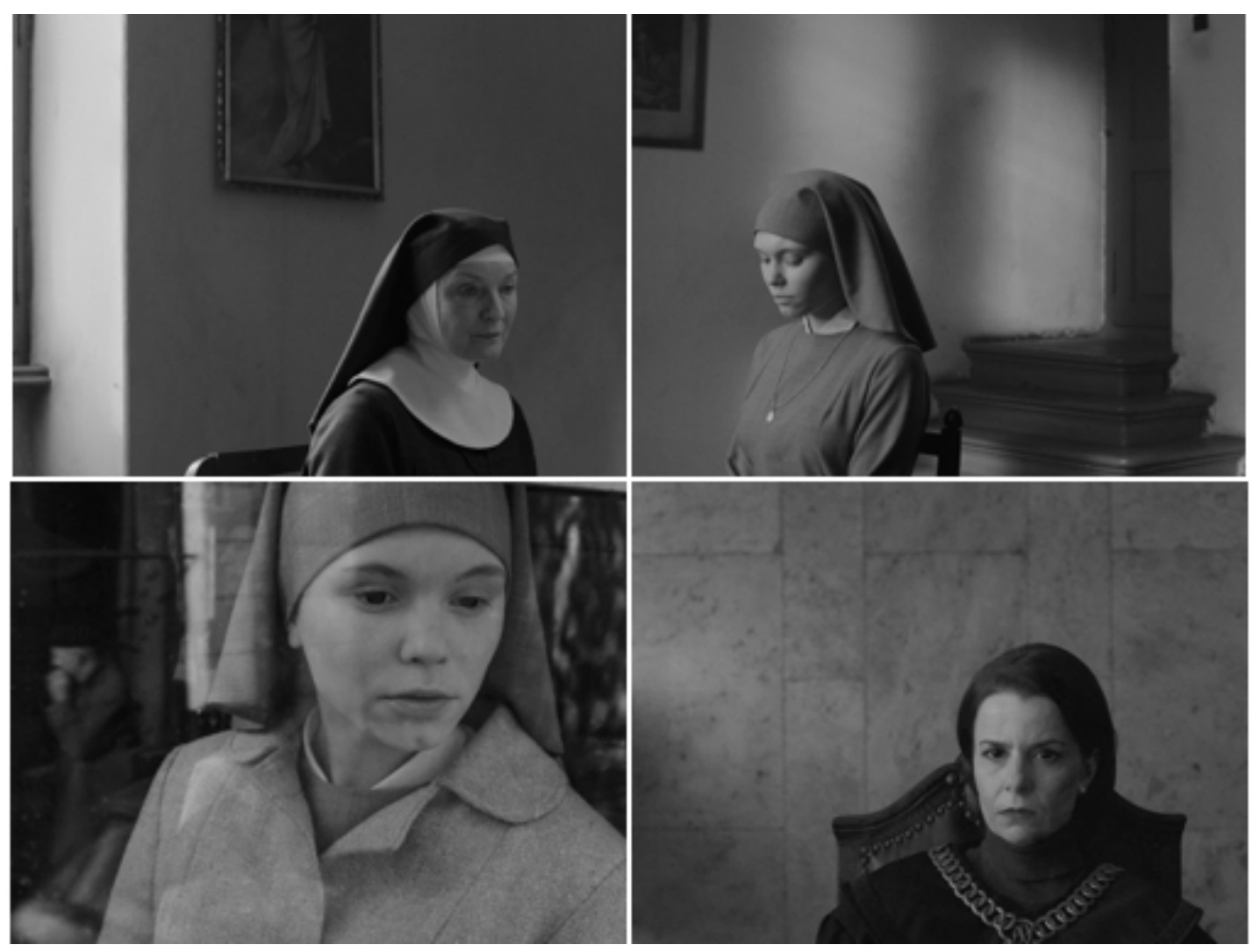

F1. Ida, Pawel Pawlikowski, 2013.

Por su parte, la presentación de Wanda como miembro principal de un tribunal utiliza el aire superior y su posición en el cuadro para dar información relevante sobre su personaje y el estado psicológico y emocional en relación a ese aspecto de su vida (F1, inferior derecha). 


\subsection{Ida y Wanda}

El inicio de la búsqueda está marcado por el acercamiento entre Ida y Wanda a nivel personal. Este capítulo, que se entrelaza con el metraje del cuarto capítulo, se sitúa entre el minuto diez y el veinticinco.

En esta parte se puede señalar una utilización de dos primeros planos que rompen con el uso característico del aire y el posicionamiento de los personajes en el cuadro a lo largo de la película. El primero de ellos es en el viaje de ida hacia el pueblo donde esperan recabar información sobre el lugar donde se encuentran enterrados los cadáveres de sus familiares. Ida mira la carretera en un primerísimo primer plano donde se corta tanto el aire superior como el inferior, encerrando a la protagonista para hacer aparecer la reflexión sobre su situación a nivel interno sin necesidad de ser explicado con diálogos (F2, izquierda). El segundo de los primeros planos repite esta fórmula con el personaje de Wanda tras recibir una respuesta negativa por parte de los aldeanos a los que han interrogado, es decir, en el viaje de vuelta que realizan (F2, centro).

Estos dos primeros planos muestran de nuevo que el uso del formato académico ayuda a cerrar el espacio de respiración de los personajes. Su uso genera un efecto muy concreto que se podría perder en la horizontalidad de una relación de aspecto más panorámica. Por tanto, a pesar de tratarse de elementos propios de la composición institucional, su uso específico de forma concreta y puntual para subrayar momentos importantes para el transcurso de la historia y la evolución de los personajes, indica que está acompañado de elementos figurativos y reflexivos propios de la (des)composición.

En este capítulo también se puede señalar el uso de composiciones con aire superior exagerado. Entre ellas destaca el plano con el que se cierra el capítulo, en el que Ida y Wanda comparten espacio -como sucede en pocas ocasiones a lo largo de la película en planos más cerrados- y ahogamiento en la parte inferior del cuadro, representando así la derrota en esta fase de su búsqueda (F2, derecha). 


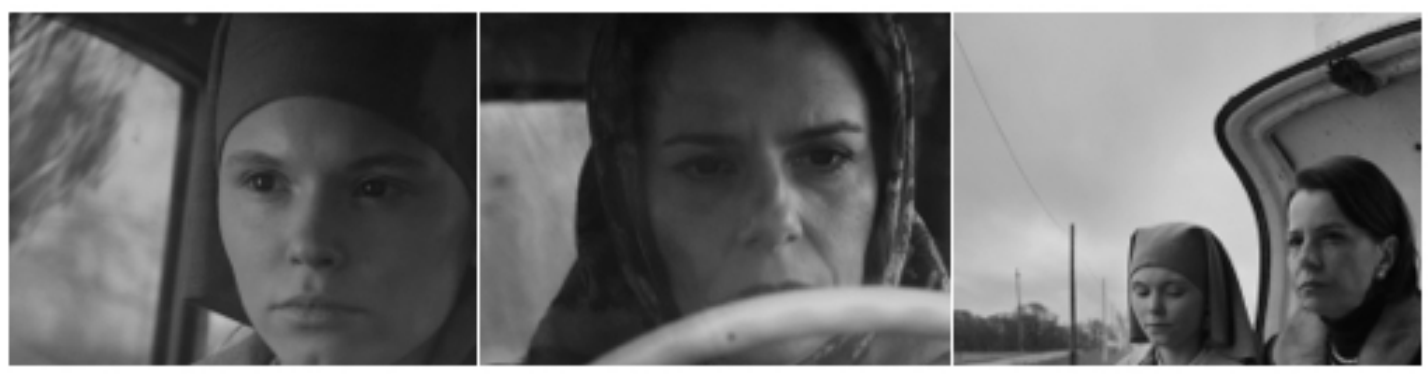

F2. Ida, Pawel Pawlikowski, 2013.

\subsection{Lis, primer encuentro}

Tal y como se ha apuntado, este cuarto capítulo forma parte de la búsqueda. No obstante, la aparición del personaje masculino le atribuye una categoría propia en tanto que primordial para la trama en relación al conflicto interno de Ida y su despertar a los placeres terrenales. Este primer encuentro se sitúa entre el minuto veinticinco y el treinta y ocho.

Este capítulo hace uso de la composición en la línea del estilo marcado de forma general, con función más estética en los planos de la actuación musical, aunque permita también describir el espacio del concierto incluyendo elementos no habituales que sirven para generar un ambiente determinado.

A nivel de montaje este es el capítulo en el que se suceden asociaciones de miradas entre Ida y Lis -el desconocido al que recogen en la carretera y que resulta ser uno de los músicos que toca en el hotel donde Ida y Wanda deciden alojarse-. El interés de Ida se repite en diferentes situaciones: el viaje en coche, el ensayo de la banda y finalmente la actuación nocturna a la que acude tras haberse negado anteriormente.

Este último es uno de los momentos en que la (des)composición vuelve a jugar un papel relevante ya que la decisión de Ida se refuerza con elementos del cuadro y su movimiento interno, dando a entender al espectador que se trata de un descenso. Esto, a su vez, permite hacer la asociación de que se desciende al plano terrenal, un descenso que está cargado de líneas que desequilibran el cuadro y que sitúan a Ida en una situación desafiante ( $F_{3}$, fotogramas superiores). 
Tras el descenso se produce el primer encuentro entre Ida y Lis a solas, caracterizado por un exterior en el que la (des)composición acentúa el uso del aire superior y del aire relacionado con la interacción entre personajes que dialogan. Además aparecen líneas que rompen el equilibrio, tal y como se puede observar en la figura 3 (fotogramas inferiores): Ida situada en el extremo izquierdo, hace referencia a la ruptura del aire en diálogo, mientras en el plano general conjunto es donde el aire superior y las líneas toman el mayor protagonismo como elemento definitorio de las emociones implicadas en ese momento.

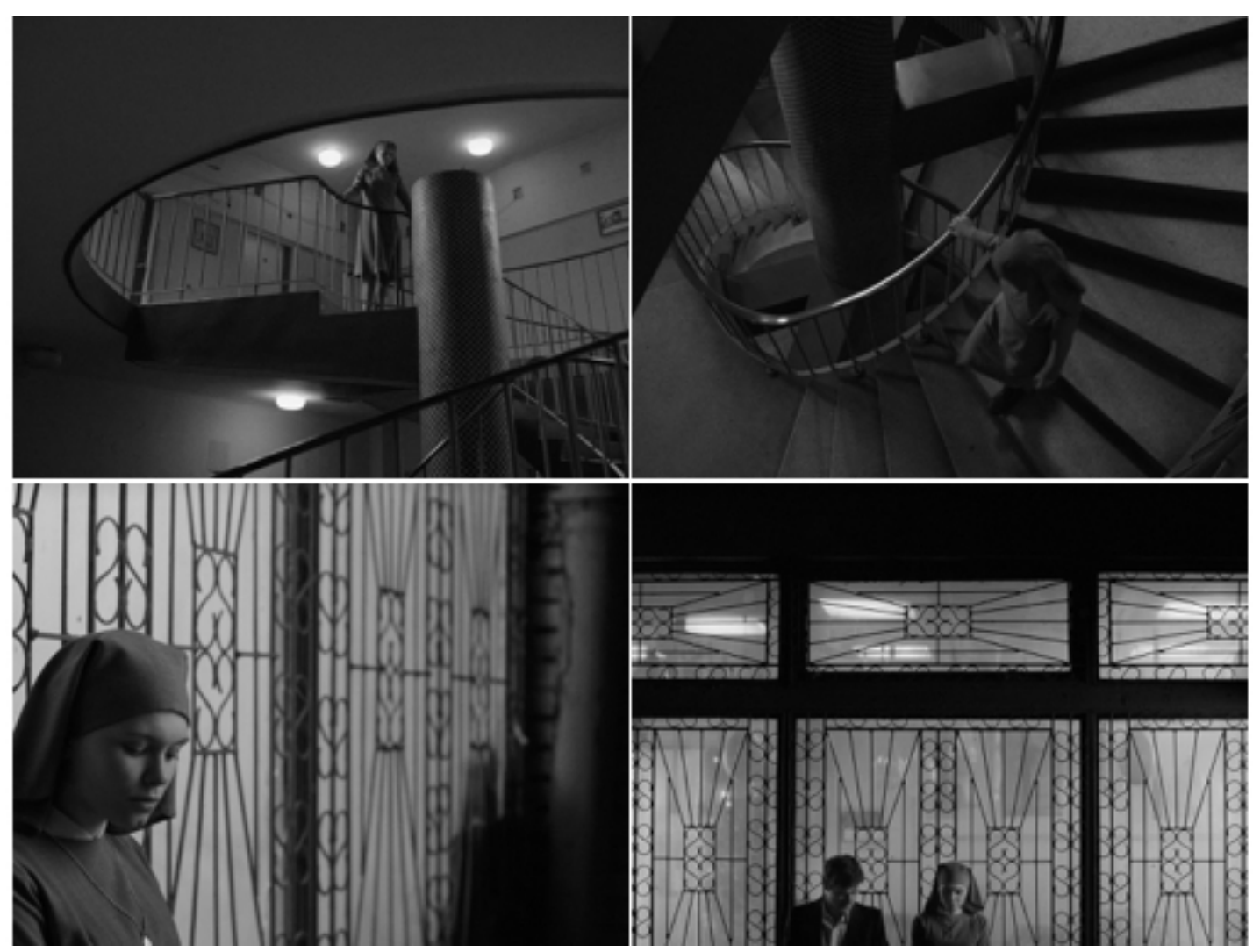

F3. Ida, Pawel Pawlikowski, 2013.

\subsection{Final de la búsqueda y segundo encuentro}

Este quinto capítulo -desde el minuto treinta y ocho hasta el cincuenta y siete- incluye la revelación de la información necesaria para terminar la búsqueda, así como el hallazgo de las tumbas. El segundo encuentro entre Ida y Lis se produce como intermedio entre esta revelación y el viaje al lugar donde se encuentra la tumba. 
En primer lugar, a pesar de seguir utilizando el elemento del aire superior como definitorio, en la escena en la que Wanda e Ida reciben la información, la interacción de los personajes a partir del diálogo sigue en esta ocasión las normas institucionales del uso del aire en tanto que el enfrentamiento no es esencial, sino que se trata de un momento de intercambio de información y de encuentro entre personajes. Por tanto, se puede comprobar un uso institucional que se refuerza gracias a los momentos en los que se rompe ese equilibrio al que el espectador está habituado (F4, fotogramas superiores).

En cuanto al segundo encuentro entre Ida y Lis, el plano conjunto es más cercano que el anterior y más institucional, a pesar de que su conversación se produce en un único plano secuencia que sigue estando alejado de los personajes -aunque mucho más cerca que en el primer encuentro-. Sin embargo, el elemento esencial es el desenlace de la secuencia, con un plano medio de Ida caracterizado por el estilo de la película situando la información en la parte inferior del cuadro. En este caso, la información más relevante se produce a través de una acción concreta: Ida se despoja del velo, dejando por primera vez su cabello a la vista, con lo que su evolución como personaje se señala al espectador incluyendo el desequilibrio de la (des)composición que indica también la tensión del conflicto interno (F4, fotogramas inferiores).

En tercer y último lugar, el hallazgo de las tumbas -que se divide entre el hallazgo y la visita posterior- vuelve a servirse del poder psicológico de la (des)composición, ahogando a los personajes a través de los límites del cuadro o a través de su posicionamiento en el extremo inferior de la imagen, a lo que se suma en ocasiones el uso del aire en relación a la posición de los personajes implicados.

La visita posterior de Ida y Wanda es una de las secuencias explicadas con mayor cercanía a la acción, convirtiendo el plano medio en esencial para explicar como excavan la tierra para enterrar en ella los restos. En esta ocasión el uso de la composición sigue de forma genérica los parámetros institucionales donde la acción se muestra a través de planos medios. 




F4. Ida, Pawel Pawlikowski, 2013.

\subsection{Vuelta al convento}

El retorno de Ida al convento -desde el minuto cincuenta y siete hasta el sesenta y tres- permite obtener observaciones esenciales para el análisis.

En primer lugar, cabe señalar la evolución del personaje en el sentido carnal a partir de la escena del baño, donde la iluminación y la (des)composición se conjugan para que el espectador comprenda el conflicto creciente de la protagonista mediante un montaje en el que su vista se fija en el cuerpo de otra chica, exagerando la presencia más destacada del reflejo del fuego en el rostro de Ida en el siguiente plano. Además, el corte deliberado del cuadro en lo que Ida observa, exagera la importancia del cuerpo como centro de la imagen. Esto se consigue a través del trabajo de (des)composición durante todo el film. En este momento, la desaparición del aire en el tercio superior encerrando dos cuerpos en el centro de la imagen -sin importar sus cabezasimpide dejar dudas al espectador sobre su significado. Por tanto, como en casos anteriores, el (des)encuadre como elemento de la (des)composición 
permite reforzar la potencia significante del encuadre institucional ( $\mathrm{F}_{5}$, fotogramas superiores).

Este elemento de duda interior se refuerza a lo largo del capítulo, tanto en escenas previas como posteriores. Uno de los planos representa este momento de duda con la soledad de Ida junto a la estatua de Cristo que han situado en el jardín al inicio del film. En este plano general la (des)composición aparece encerrando al personaje en un espacio sin salida, haciendo de la tierra el único horizonte y sin presencia de cielo.

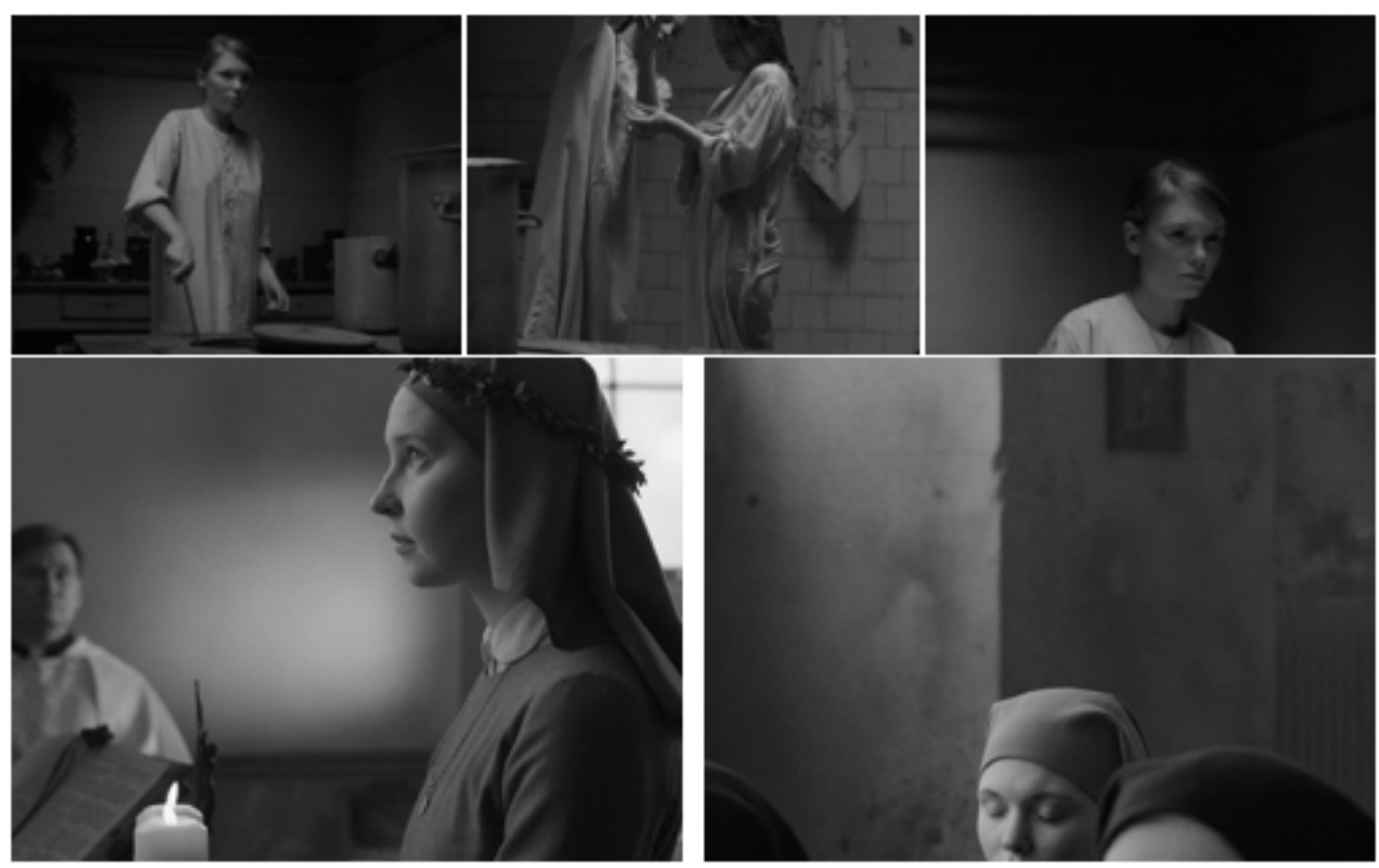

F5. Ida, Pawel Pawlikowski, 2013.

Sin embargo, el aspecto más destacable aparece gracias a la diferencia en el tratamiento de los personajes que componen la diégesis. En este sentido, el final del capítulo es ejemplificador del uso diferenciado de la composición para reforzar el estado emocional y psicológico de los personajes, así como para utilizar los elementos propios de la composición que hacen avanzar la historia y ofrecen al espectador información relevante a partir de encuadres a los que está habituado junto a otros en los que la (des)composición obliga a buscar un significado. Este aspecto se refuerza con la comparación a través del montaje. Tal y como se puede observar en la figura 5 (fotogramas inferiores), el uso de la composición es deliberado al presentar a una de las 
novicias a partir de una composición institucional y presentar seguidamente la reacción de Ida con su posición extremada en la zona inferior de la imagen, una posición a la que no se ha llegado antes ni se llegará después en la película.

\subsection{Suicidio}

El suicidio de Wanda y la posterior transformación de Ida, asumiendo la personalidad de su tía, y el posterior entierro, se sitúan entre el minuto sesenta y dos y el setenta y uno.

En este capítulo aparecen de nuevo elementos de posicionamiento de los actores en el tercio inferior de la imagen para reforzar el peso y desequilibrio en la situación que experimentan, siendo el personaje de Wanda el que queda cargado de una fuerte tensión psicológica previa al suicidio (F6).



F6. Ida, Pawel Pawlikowski, 2013.

En el reemplazo de la figura desaparecida, Ida viste la ropa de su tía y trata de fumar y beber tal como lo hacía ella. Como en ocasiones anteriores, en este caso también se utiliza una composición institucional en tanto que el 
primer plano busca reforzar los aspectos emocionales que vive el personaje con la expresión propia de un primer plano tradicional.

\subsection{Sexo}

El final de la transformación de Ida y el cierre del conflicto interno transcurre entre el minuto setenta y uno y el setenta y cinco, justo antes de que la protagonista abandone el piso tras tener relaciones sexuales con Lis.

En primer lugar, durante la actuación de Lis, el cambio de la (des)composición a la composición de Ida es fundamental para situarla en un espacio de tranquilidad más cercano a la normalidad. El cambio se produce por la desaparición del aire del tercio superior, ese peso invisible que acompaña a los personajes en la mayor parte de la película, así como el aire limitado contra el cuadro, que en esta ocasión sí deja respirar la dirección de las miradas, uniendo a los personajes a pesar de no compartir plano. En este caso también es importante señalar la importancia de la (re)composición entendida como cambio de ángulo y composición a partir del cambio de plano, ya que se produce en los dos personajes, Ida y Lis (F7).

Este retorno a la composición institucional se mantiene en la secuencia de sexo y posterior desenlace, tratándose de una composición donde no aparece un uso exagerado de los aires ni el límite de cuadro, sino que se acercan a la tipología de planos cerrados y conjunto institucionales. Este aspecto, unir a los personajes en el plano, es destacable en tanto que se trata de una película donde la composición se trabaja de forma mayormente individualizada y los planos conjuntos toman un significado extra al reunir a personajes solitarios en un espacio común.

No obstante, la secuencia también cuenta con el retorno del peso del espacio tan solo en la protagonista (F8, fotograma superior derecho), momento culminante en la transformación de Ida donde la composición sirve para aumentar la complejidad y el peso narrativo del momento. 


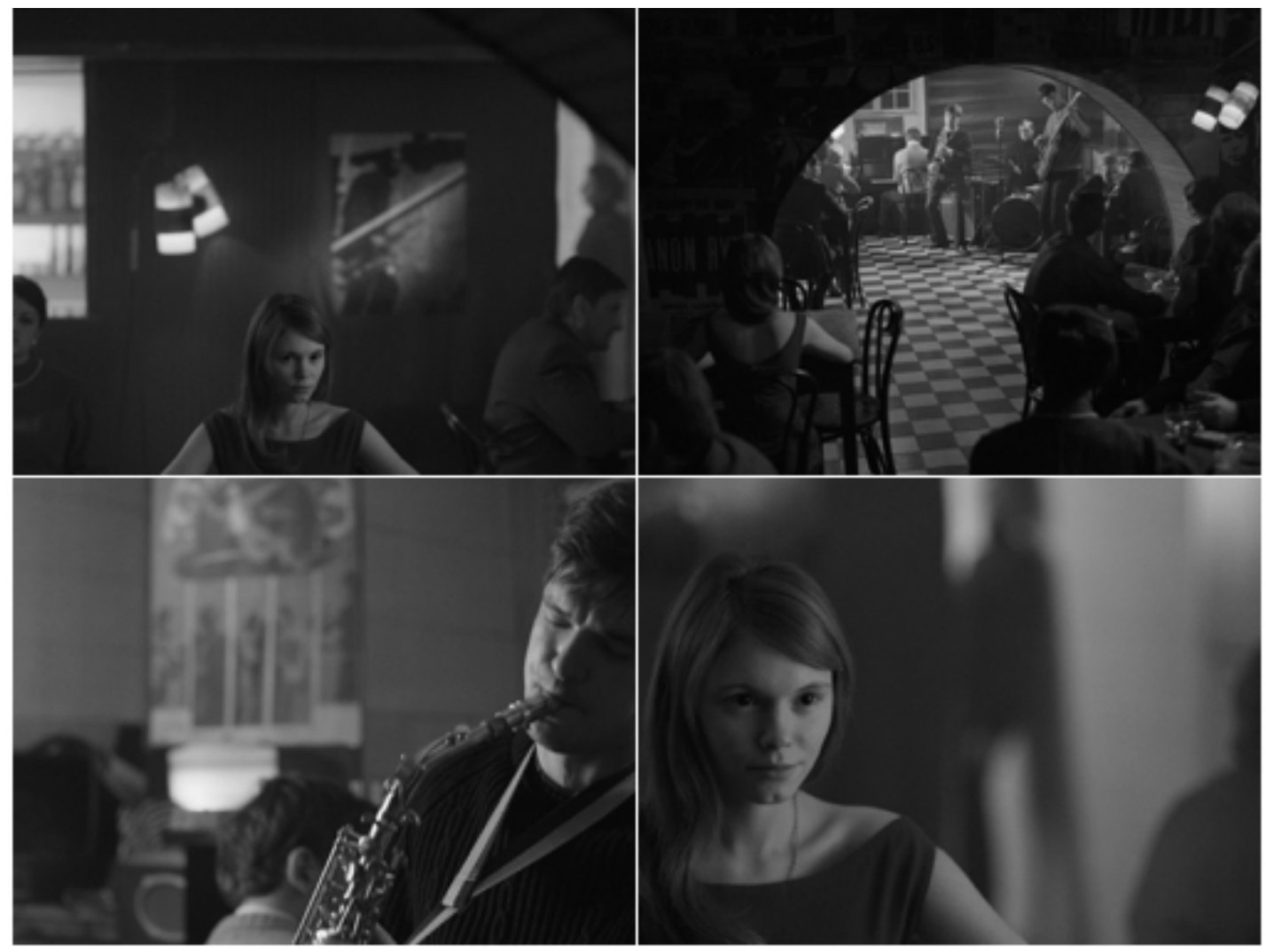

F7. Ida, Pawel Pawlikowski, 2013.



F8. Ida, Pawel Pawlikowski, 2013. 


\subsection{Cierre}

Los dos últimos minutos y medio sirven como cierre e incluyen factores relacionados con aspectos que anteriormente han sugerido información a través del uso de la (des)composición o de la acción.

Para empezar, al abandonar la casa de Wanda mientras Lis duerme, Ida se coloca de nuevo el velo, justo antes de salir. Con este acto cierra su fase de experimentación, igual que en el capítulo cinco lo había iniciado al quitárselo.

En segundo lugar, su recorrido por la ciudad es en esta ocasión con un seguimiento en movimiento, en el que la cámara está situada en el ferrocarril de nuevo (tal como sucedía en el capítulo dos), observando avanzar a Ida con determinación. En esta ocasión no nos identificamos con su mirada cargada de desconfianza hacia el mundo real, sino que es ella la que camina con resolución como parte de la ciudad, cerrando con esto el arco de la protagonista y mostrando, con una composición paralela a la utilizada al inicio, la evolución que se ha producido.

Finalmente, el último plano de la película rompe con el estilo marcado hasta el momento. No lo hace en relación a la composición, ya que Ida continúa estando centrada en un cuadro en el que vuelve a haber aire en la zona superior. No obstante, por primera vez en el film, se incluye la cámara en mano en movimiento, rompiendo el estatismo fotográfico de toda la película de forma expresamente acentuada.

\section{Conclusiones: (des)componer para construir}

Retomando el final del análisis, podemos preguntarnos si la recuperación del aire superior es una alusión al retorno de Ida a la vida monacal. Sin duda, puede sugerirse ese significado en tanto que el uso de este elemento es muy acusado en todas las secuencias relacionadas con el convento y la espiritualidad de Ida. Sin embargo, el enigma no puede responderse de forma tajante. Ni siquiera puede responderse, como apuntaba el propio 
director, que ese espacio sea el que ocupa Dios o su ausencia. Su interpretación queda abierta al espectador y sin una respuesta concluyente.

En cualquier caso, el análisis realizado muestra el poder psicológico del plano (o cuadro) en tanto que la composición toma un protagonismo absoluto, tal y como sucede en la fotografía y la pintura. A este uso del espacio asociado a otras artes figurativas, hay que añadir la duración de cada plano, una duración que permite detenerse en la lectura de cada imagen, acentuando la relación entre duración y (des)composición y entre fotografía, pintura y cinematografía, ya que esta ruptura de lo institucional implica la necesidad de leer cada cuadro con detenimiento. Es, por tanto, posible afirmar que cuando se toma conciencia de la necesidad de leer la imagen más allá de sus significantes básicos, el cineasta debe detenerse y ofrecer al espectador un momento de reflexión asociado a una estética diferente y que implica un significado nuevo: "la relación entre duración y contenido es un potente instrumento de condicionamiento y dinamización de la mirada" (Siety, 2004, p. 43).

El análisis muestra también que la utilización de diferentes modos de (des)composición puede servir para ampliar la información y el significado de cada una de sus imágenes así como de la conjunción de las mismas. En concreto, se puede afirmar que la (des)composición en Ida incluye elementos de la composición figurativa -rompe con las normas institucionales para generar efectos figurados con los que el espectador debe enfrentarse para extraer significados que van más allá de los asociados a aspectos básicos de la composición institucional-y reflexiva -tal y como Pawlikowski señala:

Siento que he visto muchas películas similares con poco que decir y que usan los mismo viejos trucos [...]. Hay muy pocas películas donde la forma tiene algo que ver con el contenido, posiblemente porque acostumbra a haber poco contenido (Bergery, 2014, p. 56).

Además de figurativa y reflexiva, la composición también puede considerarse aleatoria, tal y como se puede extraer de citas anteriores que indican que el estilo de la película no fue generado a partir de una reflexión intelectual sino más bien a partir de un hallazgo durante su producción. 
En concreto, el análisis también señala que la (des)composición se utiliza como aspecto descriptivo de la evolución del personaje. En función de los aspectos a resaltar, la composición o (des)composición escogida funciona para generar una significación extra que aparece gracias a la comparación y a la fusión de los elementos que están presentes y de los que no lo están, así como por su posicionamiento en el cuadro, utilizando diferentes tensiones para generar significados psicológicos y emotivos sin los que sería imposible comprender el arco del personaje principal. Es decir, el espacio y el significado se entrelazan de forma necesaria para el desarrollo de la diégesis gracias al uso de la (des)composición en un contexto marcado por características fotográficas de la época que se representa en la ficción.

En definitiva, a partir de la conjunción de estas tres acepciones -composición figurativa, reflexiva y aleatoria- Ida huye del estilo institucional, generando una mirada diferente. Por tanto, la (des)composición en Ida sirve para generar un espacio vacío y lleno al mismo tiempo que acerca a Pawlikowski a alguno de sus referentes -como Dreyer o Bresson- cargando de una reflexión psicológica y existencial tanto las imágenes como su recepción.

\section{Referencias bibliográficas}

Abela, J. A. (2003). Las técnicas de Análisis de Contenido: una revisión actualizada. Centro de estudios andaluces. https://goo.gl/tX6JHb

Abraham, E., Dzieciol, P., Puszczynska, E. (Productores), \& Pawlikowski, P. (Director). (2013). Ida [Película]. Polonia, Dinamarca, Italia: Opus Film, Phoenix Film, Portobello Pictures.

Albero, E. (2014). Contemplativo y atemporal. Caimán. Cuadernos de Cine. Vol. 25(76), 45 .

Arnheim, R. (1982). The power of the center. A study of Composition in the Visual Arts. Londres: University of California Press.

Aumont, J. (1992). La imagen. Barcelona: Paidós Comunicación.

Bergery, B. (2014). Divine purpose. American Cinematographer, Vol. 95(5), 54-63.

Bonitzer, P. (orig. 1978). Décadrages. Cahiers du Cinéma, Vol. 284. En Wilson, D. (ed.) (2000), Cahiers du Cinéma, Volume Four, 1973-1978: History, Ideology, Cultural Struggle (pp. 197-203). Londres: Routledge. 
Brown, B. (2012). Cinematography. Theory and Practice (2nd Edition). Oxford: Focal Press.

Burch, N. (1970). Praxis du cinéma. París: Gallimard.

De Pablos, J. (2005). La pintura y su influencia en el cine. Una aproximación pedagógica a la obra de Edward Hopper. Enseñanza, Vol. 23, 103-114.

Fonsmark, A. (2007). Hammershøi-Dreyer. La màgia de les imatges. En M. Palà (Coord.), Hammershøi i Dreyer (pp. 14-25). Barcelona: Centre de Cultura Contemporània de Barcelona i Institut d'Edicions de la Diputació de Barcelona.

Igartua, J. J., \& Humanes, M. L. (2004). El método científico aplicado a la investigación en comunicación social. Portal de la comunicación. $U A B$, Aula abierta. Lecciones básicas. https://goo.gl/zWU7Mk

Konigsberg, I. (1993). The Complete Film Dictionary. Londres: Bloomsbury.

Larumbe, N. (2014). Un viaje de vuelta. Cameraman, Vol. 74, 20-29.

Mast, G. (1984). On framing. Critical Inquiry, Vol. 11(1), 82-109.

Murch, W. (1992). In the Blink of an Eye (2nd Edition). Los Ángeles: SilmanJames Press.

O'Rawe, D. (2011). Towards a poetics of the cinematographic frame. Journal of Aesthetics \& Culture, Vol. 3, 1-13. DOI: 10.3402/jac.v3io.5378

Roda, S. (2015). Edward Hopper: la cinematografía de lo pictórico. Revista Latente, Vol. 13, 81-100.

Sánchez-Biosca, V. (1991). Teoría del montaje cinematográfico. Valencia: Filmoteca de la Generalitat Valenciana.

Sevin, A. (2007). Margins of the image: framing and deframing in the graphic novel and the film $V$ for Vendetta. Tesis de Máster. Ankara: Bilkent University.

Siety, E. (2004). El plano. Barcelona: Paidós. 